Article

\title{
Total Aglycones from Marsdenia tenacissima Increases Antitumor Efficacy of Paclitaxel in Nude Mice
}

\author{
Rui-Jing Zhu, Xiao-Ling Shen *, Ling-Lin Dai, Xiang-Ying Ai, Ru-Hua Tian, Rong Tang and \\ Ying-Jie Hu *
}

Laboratory of Chinese Herbal Drug Discovery, Tropical Medicine Institute, Guangzhou University of Chinese Medicine, Guangzhou 510405, China

* Authors to whom correspondence should be addressed; E-Mails: xshen2@gzucm.edu.cn (X.-L.S.); yingjiehu@gzucm.edu.cn (Y.-J.H.); Tel.: +86-20-3658-5456 (X.-L.S.); +86-20-3658-5143 (Y.-J.H.); Fax: +86-20-8637-3516 (X.-L.S. \& Y.-J.H.).

Received: 6 August 2014; in revised form: 23 August 2014 / Accepted: 1 September 2014 /

Published: 5 September 2014

\begin{abstract}
Marsdeniae tenacissimae Caulis (MTC) is a Chinese herbal medicine used mainly for treatment of cancer, whose pharmacologically active constituents responsible for its in vivo activity and clinical efficacy have not been clearly elucidated. In this study, total aglycones of MTC (ETA) showed the ability to sensitize KB-3-1, HeLa, HepG2 and K562 cells to paclitaxel treatment. More inspiringly, ETA markedly enhanced the antitumor activity of paclitaxel in nude mice bearing HeLa or KB-3-1 xenografts. Compared to treatment with paclitaxel alone, treatment with combination of paclitaxel and ETA achieved significant reduction in volume and weight of HeLa tumors $(p<0.05)$, and remarkable inhibition to the growth of KB-3-1 tumors $\left(p<10^{-6}\right)$. ETA was characterized by the presence of a group of tenacigenin $B$ ester derivatives, among which four reference compounds, $11 \alpha$-O-tigloyl-12 $\beta$ - $O$-acetyltenacigenin B, $11 \alpha, 12 \beta$-di- $O$-tigloyltenacigenin B, $11 \alpha-O-2$-methylbutanoyl-12 $\beta$ - $O$-tigloyltenacigenin $\mathrm{B}$, and $11 \alpha-O-(2-$-methylbutanoyl)-12 $\beta$ $O$-benzoyltenacigenin $\mathrm{B}$, accounted for $42.14 \%$ of the total peak area of 19 detectable components assayed by HPLC. Our study has identified ETA as a promising sensitizer for cancer chemotherapy.
\end{abstract}

Keywords: Marsdeniae tenacissimae Caulis; total aglycones; polyoxpregnane; paclitaxel; HeLa; KB-3-1; chemosensitizer 


\section{Introduction}

Cancer is one of the major diseases in China. In 2009, there were 3.12 million new cases diagnosed with cancer, and up to 2.7 million patients died of cancer. Surgery, radiation and drugs are effective means for treatment of cancer, but the average five-year survival rate of cancer patients is only $20.0 \%-30.0 \%$ [1]. A main cause for the high cancer mortality is drug resistance. Tumors have either intrinsic or acquired resistance to a number of anticancer agents, leading to therapeutic failure [2]. Natural products of plant origin play very important roles in research and development of cancer therapeutics [3]. For example, a number of clinically used anticancer drugs are of plant origin, including the Vinca alkaloids, taxanes, podophyllotoxins, and camptothecins [4-6]. Marsdeniae tenacissimae Caulis [origin: dried stems of the Asclepiadaceous plant Marsdenia tenacissima (Roxb.) Wight et Arn] is a Chinese herbal medicine used for the treatment of coughs, rheumatism, carbuncles and tumors [7]. A water soluble extract of M. tenacissimae (MTE) is used as raw material for Xiao-Ai-Ping injection (XAP), a Chinese herbal drug approved for the treatment of cancer [8]. If co-administered with anticancer agents such as platinum drugs XAP is reported to be able to enhance the clinical effects of chemotherapy in the treatment of lung cancer, liver cancer or gastric cancer, etc. $[9,10]$. Pharmacological studies showed that XAP or its chloroform extract may increase gefitinib sensitivity in drug resistant non-small cell lung cancer cells [11], sensitize MG63 cells to doxorubicin-induced apoptosis [12], induce apoptosis of hematologic neoplasm cells [13], or affect angiogenesis [14]. So far, more than 40 pregnane derivatives were identified from M. tenacissima [15], and several of them were reported to be cytotoxic to cancer cell lines [16], or capable of reversing multidrug resistance in Pgp overexpressing HepG2 cells [17]. Though the pharmacologically active constituents in MTC have not been clearly elucidated yet, liposoluble pregnane derivatives are thought to be responsible or partially responsible for its in vivo anticancer or chemosensitizing activities [11-18]. In this study, a hydrophobic extract of total pregnane aglycones (ETA) was obtained from the hydrolytic product of the crude glycosides of MTC. The possibility for clinical usage of ETA in combination with chemotherapy for treatment of human cancers, in vitro and in vivo activity of ETA in increasing antitumor effect of paclitaxel (taxol), as well as a quality control method for ETA were investigated.

\section{Results and Discussion}

\subsection{Enhanced Inhibitory Effect of Paclitaxel on Cell Viability by ETA}

In the human hepatoma cell line HepG2, leukemia cell line K562, oral epidermoid carcinoma cell line KB-3-1 and human cervical cancer cell line HeLa, cell viabilities in the presence of $10 \mu \mathrm{g} / \mathrm{mL}$ of ETA were over $98 \%$, thus $10 \mu \mathrm{g} / \mathrm{mL}$ was chosen as the working concentration of ETA in investigations of the ability of ETA to enhance the in vitro anticancer activity of paclitaxel. Paclitaxel concentrations that inhibited $50 \%$ of cell viability $\left(\mathrm{IC}_{50}\right)$ in the absence or presence of $10 \mu \mathrm{g} / \mathrm{mL}$ ETA in K562, HeLa, KB-3-1 and HepG2 cell lines were measured and compared. As shown in Table 1, addition of $10 \mu \mathrm{g} / \mathrm{mL}$ of ETA significantly decreased the $\mathrm{IC}_{50}$ values of paclitaxel in HeLa, HepG2 and KB-3-1 cells, implying that the anticancer activity of paclitaxel in the three cell lines was enhanced by ETA. 
Table 1. $\mathrm{IC}_{50}$ values of paclitaxel in human cancer cell lines $(\mathrm{ng} / \mathrm{mL})$. Cancer cells were treated with various concentrations of paclitaxel alone (Control) or in the presence of $10 \mu \mathrm{g} / \mathrm{mL}$ of ETA for $48 \mathrm{~h}$. Cell viability was measured by CCK- 8 assay. Data were expressed as Mean $\pm \mathrm{SD}$ of three independent experiments. $* p<0.05$ and ${ }^{* *} p<0.01$ compared to control.

\begin{tabular}{ccccc}
\hline \multirow{2}{*}{ Treatment } & \multicolumn{4}{c}{ Tumor Cell Lines } \\
\cline { 2 - 5 } & K562 & HeLa & HepG2 & KB-3-1 \\
\hline Paclitaxel alone (Control) & $4.8 \pm 0.4$ & $17.1 \pm 4.1$ & $67.2 \pm 12.3$ & $8.1 \pm 1.3$ \\
Paclitaxel $+10 \mu \mathrm{g} / \mathrm{mL}$ ETA & $3.8 \pm 0.6$ & $8.3 \pm 1.0 *$ & $14.1 \pm 8.5 * *$ & $5.1 \pm 0.6 *$ \\
\hline
\end{tabular}

\subsection{Enhanced Inhibitory Effect of Paclitaxel on Tumor Growth in Nude Mice by ETA}

In our study, ETA actively increased the in vitro anticancer activity of paclitaxel and was therefore further investigated for its effects on the in vivo antitumor ability of paclitaxel. Nude mice bearing HeLa or KB-3-1 xenografts on their back were either given paclitaxel (Taxol) or ETA alone, or their combination. Figure 1 showed the experimental results obtained in KB-3-1 tumor bearing mice. Compared to mice treated with vehicle (vehicle group), oral administration of $250 \mathrm{mg} / \mathrm{kg} / \mathrm{day}$ of ETA for 9 days (ETA group) did not affect the body weight (Figure 1A), tumor growth trend (Figure 1B) and tumor weight (Figure 1C) of mice $(p>0.05)$; treatment with $10 \mathrm{mg} / \mathrm{kg}$ Taxol by intraperitoneal injection every other day for five doses (Taxol group) resulted in smaller tumor weight $(p<0.001$, Figure 1C) and tumor size (Figure 1D). More inspiring efficacy was observed in mice treated with a combination of Taxol and ETA: tumors completely stopped growing and even disappeared in part of the mice (Figure 1D). Compared to treatment with Taxol alone, treatment with Taxol in combination with ETA did not affect the body weight (Figure 1A), but remarkably reduced the average weight and size of tumors $\left(p<10^{-6}\right.$, Figure 1B-D), implying that ETA significantly enhanced in vivo antitumor activity of paclitaxel. The chemosensitizing effect of ETA was also observed in mice bearing HeLa xenografts. Compared to vehicle, $10 \mathrm{mg} / \mathrm{kg}$ of Taxol alone (Taxol-H), or $200 \mathrm{mg} / \mathrm{kg}$ of ETA alone (ETA-H) could not inhibit tumor growth, but the combination of $10 \mathrm{mg} / \mathrm{kg}$ of Taxol and $50 \mathrm{mg} / \mathrm{kg}$ of ETA (Taxol-H + ETA-L), or the combination of $5 \mathrm{mg} / \mathrm{kg}$ of Taxol and $200 \mathrm{mg} / \mathrm{kg}$ of ETA (Taxol-L + ETA-H) significantly inhibited tumor growth without affecting the body weight of mice (Figure 2A). Tumor weights in the two groups were much lighter than those in the other four groups (Figure 2B).

In tumor therapy, intrinsic or acquired drug resistance in tumor tissue weakens the effect of chemotherapy treatment, and more seriously, can result in treatment failure. The mechanisms of drug resistance involved include over-expression of transporter proteins such as Pgp, MRP or BCRP, over-expression of glutathione S-transferease, mutation of tumor suppressor gene p53, up-regulation of topoisomerase II or topoisomerase II gene mutation, etc. [2]. Paclitaxel is an effective drug for gynecological tumors, including breast cancer, ovarian cancer, cervical carcinoma, and carcinoma of the endometrium. Paclitaxel is also a transport substrate of Pgp, an ATP-dependent membrane transporter protein that pumps substrate drug out of tumor cells [19]. The HeLa tumor model established by subcutaneously injecting HeLa cells on the back of nude mice was reported to be highly sensitive to paclitaxel [20], but HeLa tumors in this study grew well, even when exposed to $10 \mathrm{mg} / \mathrm{kg}$ of paclitaxel, implying that in vivo HeLa tumor model established in this experiment was resistant to paclitaxel. In our study, paclitaxel or ETA alone could not inhibit tumor growth, but 
paclitaxel in combination with ETA significantly inhibited tumor growth, meaning that the paclitaxel sensitivity of the resistant HeLa tumor was restored by ETA.

Figure 1. ETA enhanced inhibitory effect of Taxol on growth of KB-3-1 tumor. KB-3-1 tumor-bearing nude mice were given $10 \mathrm{mg} / \mathrm{kg}$ Taxol (Taxol) every other day, or $250 \mathrm{mg} / \mathrm{kg} /$ day ETA (ETA), or the combination of Taxol and ETA (Taxol + ETA), or equivalent amount of vehicle (Vehicle) for 9 days. Body weight (A), tumor volume (B) and tumor weight $(\mathbf{C})$ were recorded and expressed as mean value \pm standard error of mean $(\mathrm{n}=10)$. Tumor picture was taken at the last experimental day (D). $* * p<0.01, * * * p<0.001$ and $* * * * p<10^{-6}$ compared to Vehicle group, while ${ }^{\boldsymbol{\Lambda \Delta \Lambda}} p<10^{-6}$ compared to Taxol group.

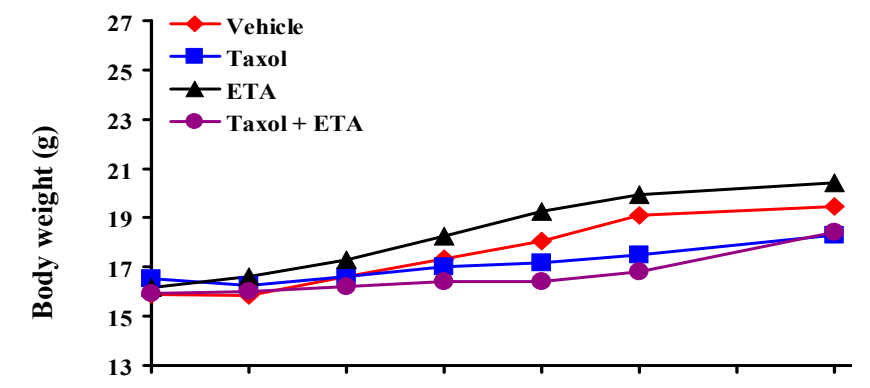

(A)

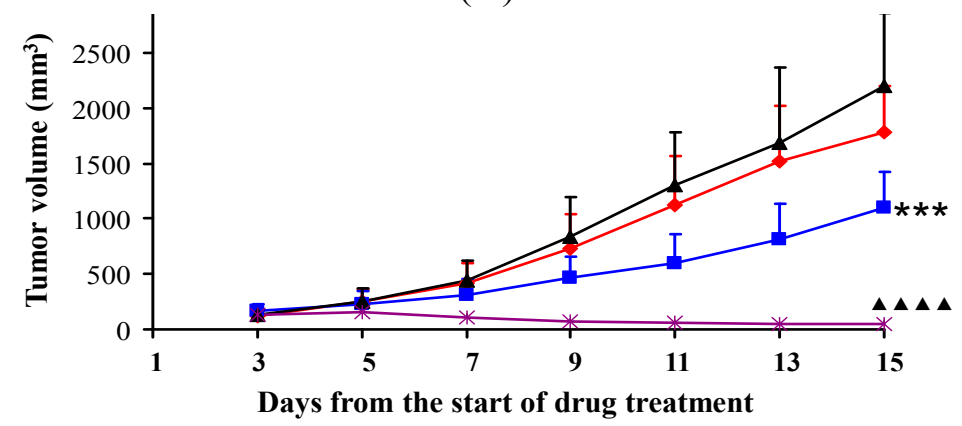

(B)

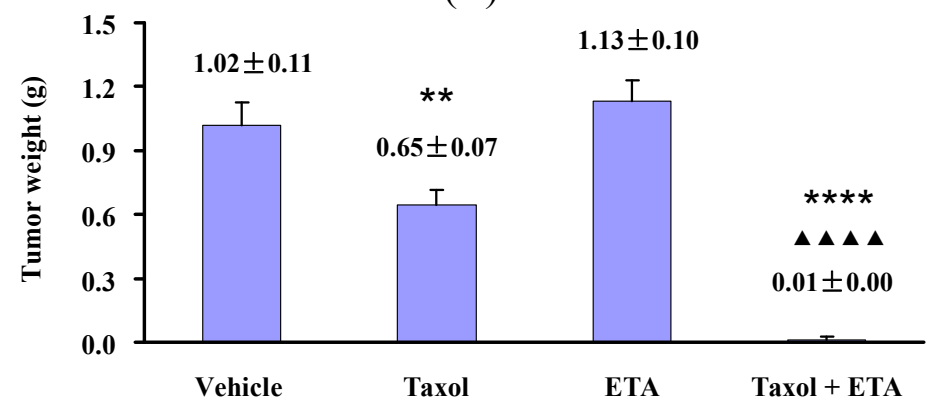

(C)

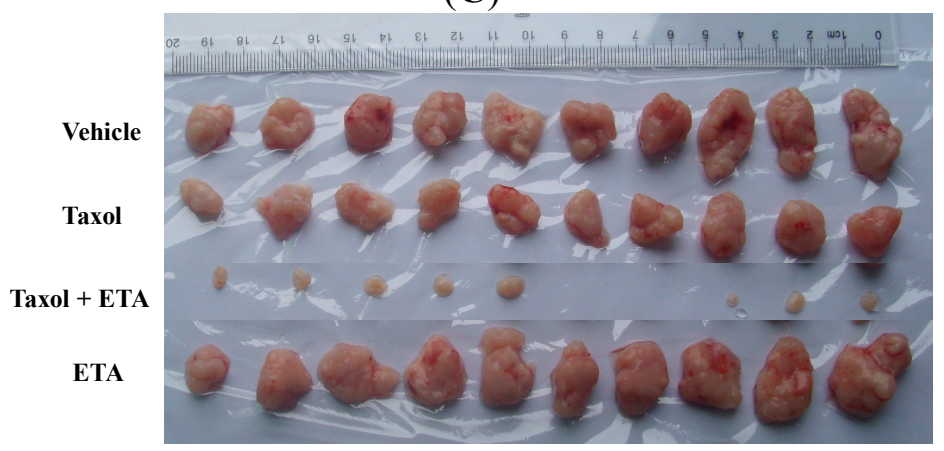

(D) 
Figure 2. ETA enhanced inhibitory effect of Taxol on growth of HeLa tumors. HeLa tumor-bearing nude mice were given $10 \mathrm{mg} / \mathrm{kg}$ (Taxol-H) or $5 \mathrm{mg} / \mathrm{kg}$ (Taxol-L) of Taxol every other day for 5 doses, or $200 \mathrm{mg} / \mathrm{kg} /$ day of ETA (ETA-H) for 9 doses, or the combination of Taxol-H and $50 \mathrm{mg} / \mathrm{kg} /$ day of ETA (Taxol-H + ETA-L), or the combination of Taxol-L and ETA-H (Taxol-L + ETA-H). Body weight (A) and tumor weight (B) were recorded and expressed as mean value \pm standard error of mean $(n=6)$. Compared to Vehicle group, data were significantly different at $* * p<0.01$. Compared to Taxol-H group, data were significantly different at $\mathbf{\wedge} p<0.05$.

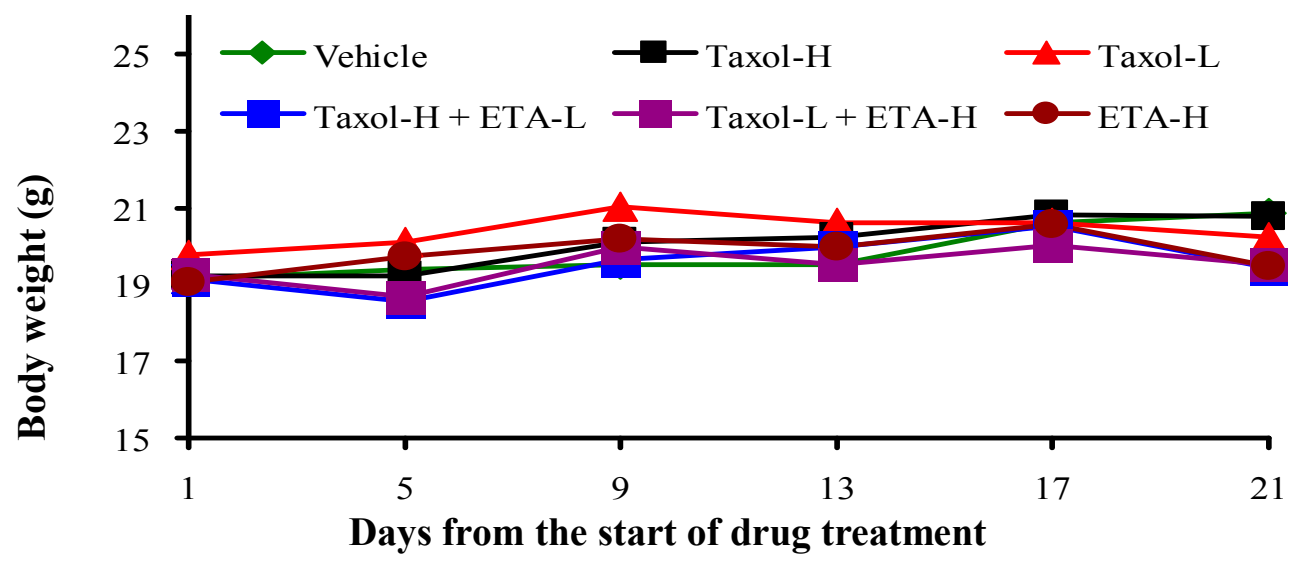

(A)

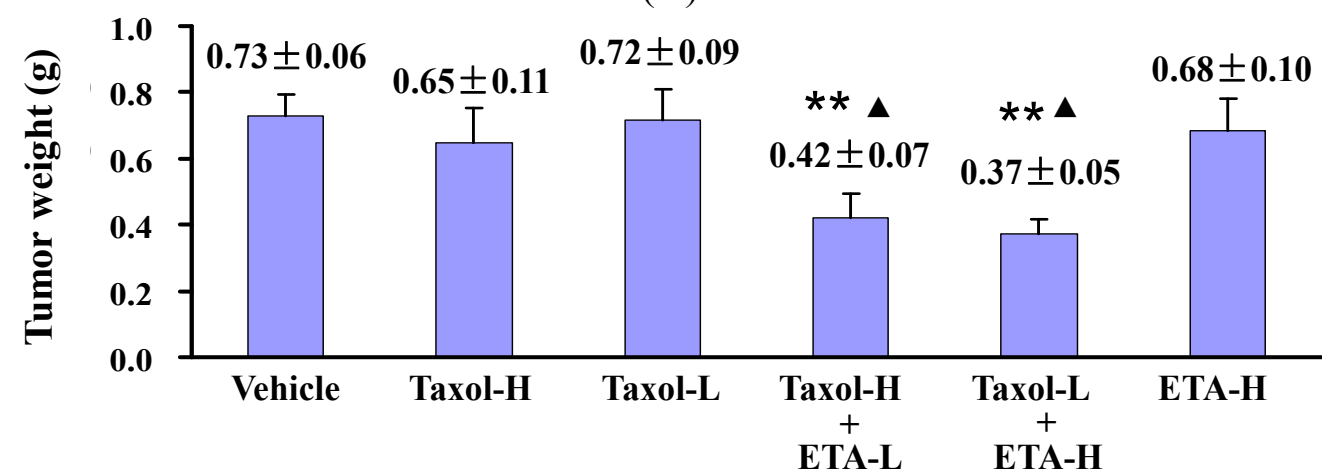

(B)

The incidence of oral cancer is high in areas where betel nut and products derived from it are socially endorsed masticatory products [21]. In our study, treatment with $10 \mathrm{mg} / \mathrm{kg}$ of paclitaxel alone significantly slowed down the growth of KB-3-1 tumors, but could not stop the tumor growth. However, when paclitaxel was given together with ETA, the growth of KB-3-1 tumors was completely inhibited.

In this study, co-administration of paclitaxel with ETA achieved much better therapeutic effect than administration of paclitaxel alone, indicating that ETA is a potential paclitaxel sensitizer in treatment of human cancer. Considering that paclitaxel is a transport substrate of Pgp while tenacigenin B derivatives could inhibit Pgp transport function [17], it is strongly suggested that ETA might work through inhibiting Pgp function. 


\subsection{Chemical Composition of ETA}

Chemical constituents of ETA were well separated through a Phenomenex Luna $\mathrm{C}_{18}$ column $(4.6 \times 250 \mathrm{~mm}, 5 \mu \mathrm{m})$ eluting with methanol (solvent A) and $0.1 \%$ aqueous acetic acid $(v / v$, solvent B), at oven temperature $30{ }^{\circ} \mathrm{C}$ and detection wavelength $230 \mathrm{~nm}$ with gradient elution: 0-30 min, $58 \%-63 \% \mathrm{~A} ; 30-40 \mathrm{~min}, 63 \%-68 \% \mathrm{~A} ; 40-70 \mathrm{~min}, 68 \%-78 \% \mathrm{~A}$. The HPLC fingerprints of ETA are shown in Figure 3A. Chromatograms of this active extract were characterized by the presence of a group of tenacigenin $\mathrm{B}$ ester derivatives, including $11 \alpha$-O-tigloyl-12 $\beta$ - $O$-acetyltenacigenin B (1), $11 \alpha, 12 \beta$-di- $O$-tigloyltenacigenin B (2), $11 \alpha-O-2$-methylbutanoyl-12 $\beta-O$-tigloyltenacigenin B (3), and $11 \alpha$-O-(2-methylbutanoyl)-12 $\beta$-O-benzoyltenacigenin B (4) (Figure 3B), which were also numbered as peaks $1-4$ in the chromatogram. According to the sum of peak area, marker compounds $\mathbf{1}-\mathbf{4}$ accounted for $42.14 \%$ content of that of 19 detectable components in ETA (Supplementary materials; Table S1).

Figure 3. Characteristic chromatograms of ETA and the markers assayed by HPLC. (A) ETA; 1-19, detectable components; (B) the mixed markers, 1-4, marker compounds 1-4. For assay, methanol solutions of mixed markers 1-4 (1.04, 1.21, 0.98, $0.96 \mathrm{mg} / \mathrm{mL})$ and of ETA $(1.42 \mathrm{mg} / \mathrm{mL})$ were used, oven temperature was set at $30{ }^{\circ} \mathrm{C}$, and detecting wavelength was set at $230 \mathrm{~nm}$.

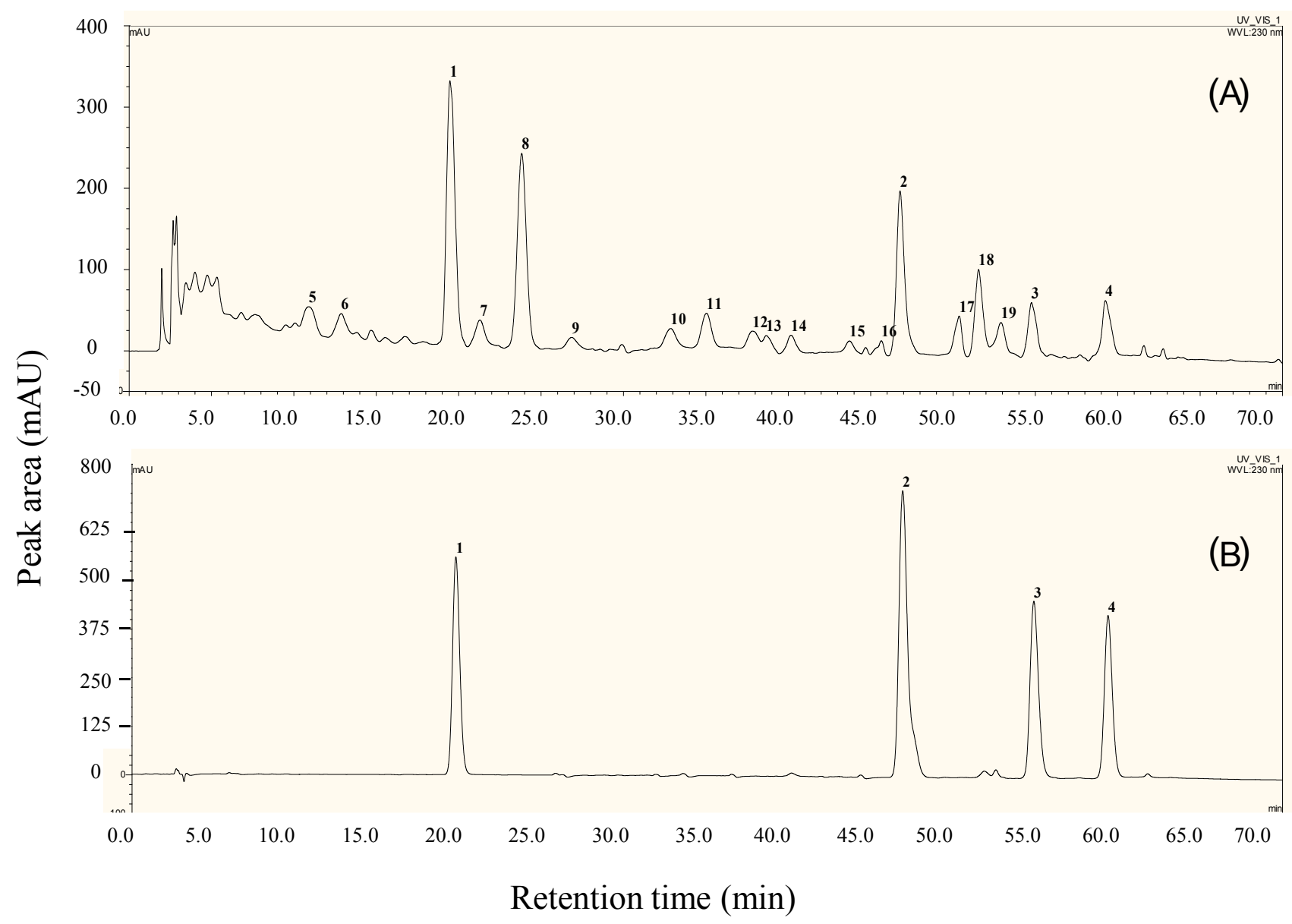




\subsection{Assay of 1}

Reference compound 1 was shown to be a major constituent of ETA (Figure 3) and was therefore measured quantitatively. The condition optimized for assay of $\mathbf{1}$ was the same as described in compositional analysis of ETA, except that isocratic elution using methanol mixed with $0.1 \%$ aqueous acetic acid $(65: 35 ; v / v)$ was chosen. The range of relative standard deviations for accuracy of peak area, repeatability of measured concentration, and stability of sample within $12 \mathrm{~h}$ were validated as $0.42 \%-0.79 \%$. The calibration curve for 1 was $\mathrm{Y}=264.04 \mathrm{X}+2.0137\left(\mathrm{R}^{2}=0.9998\right)$ with a linear range of 1.04-16.64 $\mu \mathrm{g}$. Recovery rates for spiked samples of ETA were determined as $100.65 \% \pm 1.03 \%$. Measured concentration of 1 was $11.88 \% \pm 0.50 \%(n=3)$.

\section{Experimental Section}

\subsection{Preparation of the Extract of Total Aglycones of M. tenacissima}

The plant was collected from Mengzi County, Yunnan Province, China in October 2011 and identified as Marsdenia tenacissima (Roxb.) Wight et Arn. by Fa-Guo Wang, a plant taxonomist at South China Botanical Garden, Chinese Academy of Sciences. A voucher specimen (No. 201110 sp-2) was deposited at the Chinese Herbal Drug Discovery Lab of theTropical Medicine Institute, Guangzhou University of Chinese Medicine. Dried and ground stems of M. tenacissima ( $8.0 \mathrm{~kg})$ were extracted three times with $80 \%(v / v)$ ethanol (50L) under reflux, $2 \mathrm{~h}$ each time. The combined ethanol solution was concentrated in vacuo to remove ethanol and extracted successively with petroleum ether $(\mathrm{PE})$, ethyl acetate $(\mathrm{EtOAc})$ and $n$-butanol $(\mathrm{BuOH})$. After removal of organic solvents and drying in vacuo, $\mathrm{PE}$, EtOAc, and $\mathrm{BuOH}$ extracts were obtained. EtOAc extract $(80.0 \mathrm{~g})$ showed positive Lieberman-Burchard (L-B) and Keller-Kiliani (K-K) reactions, suggesting the concentration of steroidal glycosides containing 2-deoxyhexose residues and was named as extract of total glycosides [22,23]. A sample of the total glycosides ( $40 \mathrm{~g}$ ) was dissolved in anhydrous EtOH $(500 \mathrm{~mL})$, mixed with $0.05 \mathrm{M}$ $\mathrm{H}_{2} \mathrm{SO}_{4}(500 \mathrm{~mL})$ and refluxed for $1 \mathrm{~h}$. The reactive mixture was neutralized by $10 \% \mathrm{Na}_{2} \mathrm{CO}_{3}$, distilled in vacuo to remove EtOH, and extracted with EtOAc. The EtOAc extract gave a positive L-B reaction and negative K-K reaction, suggesting the concentration of total aglycones [22,23], and was named as ETA (22 g).

\subsection{In Vitro Anticancer Activity of Paclitaxel in the Presence or Absence of ETA}

Human hepatoma cell line HepG2 and human leukemia cell line K562 were purchased from the cell bank of the Chinese Academy of Science (Shanghai, China). Human oral epidermoid carcinoma cell line KB-3-1 and human cervical cancer cell line HeLa were kindly provided by Dr. Tse AK of Hong Kong Baptist University. K562, HeLa and HepG2 cell lines were maintained in RPMI 1640 (Gibco-BRL, Grand Island, NY, USA) containing 10\% fetal bovine serum (Gibco-BRL), while KB-3-1 cell line was maintained in DMEM (Gibco-BRL) supplemented with 10\% fetal bovine serum. All cells were cultured at $37{ }^{\circ} \mathrm{C}$, saturated humidity and $5 \% \mathrm{CO}_{2}$. To examine the inhibitory effect of paclitaxel alone or in combination with ETA on cancer cell viability, $100 \mu \mathrm{L}$ per well of cell suspension containing $1 \times 10^{4}$ cells was seeded into a 96-well microplate and incubated $24 \mathrm{~h}$. Cells were then exposed to 
various concentrations of paclitaxel (Sigma/Aldrich Co., St Louis, MO, USA) in the presence or absence of ETA $(10 \mu \mathrm{g} / \mathrm{mL})$ for $48 \mathrm{~h}$. Cell viability was then measured using Cell Counting Kit-8 (Dojindo Laboratories, Shanghai, China) [24]. $\mathrm{IC}_{50}$ values of paclitaxel in the presence and absence of ETA were used to evaluate the in vitro anticancer activity.

\subsection{In Vivo Anti-Tumor Effect of Paclitaxel in the Presence or Absence of ETA}

Animal studies were approved by the Animal Ethics Committee at Guangzhou University of Chinese Medicine (Document No. syxk (Yue) 2008-0001) and performed according to its Animal Care and Use Guidelines. Female BALB/c nude mice of 4-5 weeks of age were subcutaneously injected with $5 \times 10^{6}$ of HeLa cells or $3 \times 10^{6}$ of KB-3-1 cells on the back to establish tumor xenografts $[25,26]$. Two days after KB-3-1 cell injection, mice were randomly divided into four groups (10 mice each group) and treated with $10 \mathrm{mg} / \mathrm{kg}$ of paclitaxel by intraperitoneal injection (Taxol group), or $250 \mathrm{mg} / \mathrm{kg}$ of ETA by oral administration (ETA group), or the combination of paclitaxel and ETA (Taxol + ETA group). Mice given equivalent amount of solvent (8.6\% of Cremophor EL, $8 \%$ of ethanol in saline, $10 \mathrm{~mL} / \mathrm{kg}$ by intraperitoneal injection) were set as drug negative control (Vehicle group). Drug treatment lasted for 9 days. Paclitaxel was given every other day for five doses while ETA was given orally daily. Body weight and tumor size were recorded every other day. Tumor size was monitored by measuring two perpendicular diameters with a caliper and tumor volume was calculated as volume $=$ length $\times$ width $^{2} \times 0.5$. The animal experiments were terminated 6 days after the last drug treatment by sacrificing mice according to the guidelines. Tumor xenografts were then stripped and weighed.

Twelve days after injection of HeLa cells, mice with tumors growing well were selected and randomly divided into four groups (six mice each group) and treated with $10 \mathrm{mg} / \mathrm{kg}$ (Taxol-H group) or $5 \mathrm{mg} / \mathrm{kg}$ (Taxol-L group) of paclitaxel, or $200 \mathrm{mg} / \mathrm{kg}$ of ETA (ETA-H group), or the combination of $10 \mathrm{mg} / \mathrm{kg}$ of paclitaxel and $50 \mathrm{mg} / \mathrm{kg}$ of ETA (Taxol-H + ETA-L), or the combination of $5 \mathrm{mg} / \mathrm{kg}$ of paclitaxel and $200 \mathrm{mg} / \mathrm{kg}$ of ETA (Taxol-L + ETA-H group), or equivalent volume of solvent (Vehicle group). Drug treatment lasted for 9 days and pacltaxel and ETA were given as described above. Body weights of mice were monitored routinely. The experiment was terminated 12 days after the last drug treatment and the tumor xenografts were obtained.

\subsection{Statistical Analysis}

Data were expressed as Mean \pm standard error of the mean (SEM). Effects of various treatments were analyzed by ONE-WAY ANOVA analysis. $p$ value $<0.05$ was considered statistically significant.

\subsection{Chemical Compositional Analysis of ETA}

Chemical composition of ETA was assayed by reversed phase HPLC and characterized by the presences of a group of tenacigenin B esters as marker of quality control. The reference compounds

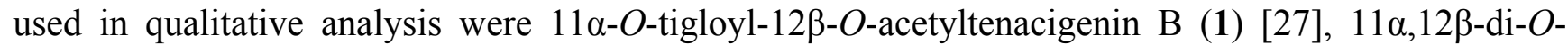

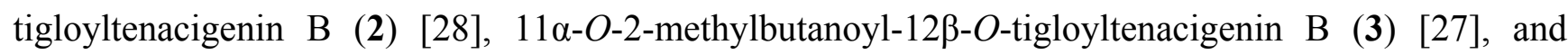
$11 \alpha-O$-(2-methylbutanoyl)-12 $\beta$-O-benzoyltenacigenin B (4) [27]. These compounds were isolated 
from ETA by chromatography, and their structures were identified by analysis and comparison on their NMR and MS data with those reported. NMR (Tables S2, S3) and MS data of 1-4 were listed in the Supplementary materials. Chromatographic conditions involving C-18 column, mobile phase, and elution manner were screened and optimized.

\subsection{Assay of Marker Compound $\mathbf{1}$}

Compound 1 was used as assay marker. Mobile phase, standard curve, linearity of calibration curve, precision, stability, reproducibility, and accuracy were verified.

\section{Conclusions}

This is the first demonstration that total pregnane aglycones (ETA) manufactured from the plant M. tenacissima markedly enhanced the anticancer activity of paclitaxel both in vitro and in vivo. Our data support the use of ETA as a sensitizer for paclitaxel treatment of cancer. Results of HPLC assays on ETA provided a basis of quality control for this chemosensitizer.

\section{Supplementary Materials}

Supplementary materials can be accessed at: http://www.mdpi.com/1420-3049/19/9/13965/s1.

\section{Acknowledgments}

This work was financially supported by the funds of Scientific and Technological Projects of Guangzhou, China (Grant number: 2011J4100058), and doctoral funds of Higher Education Institutions of China (Grant number: 20104425110014). Plant sample was collected by Mr. Wen-Xiang He at Yunnan province, China.

\section{Author Contributions}

Xiao-Ling Shen and Ying-Jie Hu designed and conducted experiments, analyzed and interpreted the data, and wrote the paper. Rui-Jing Zhu, Ling-Lin Dai, Xiang-Ying Ai, Ru-Hua Tian, and Rong Tang conducted the experiments, collected the data.

\section{Conflicts of Interest}

The authors declare no conflict of interest.

\section{References}

1. Jiang, J.; Chen, W.Q. Chinese Cancer Registry Annual Report; Military Medical Science Press: Beijing, China, 2012.

2. Ozben, T. Mechanisms and strategies to overcome multiple drug resistance in cancer. FEBS Lett. 2006, 580, 2903-2909.

3. Cragg, G.M.; Grothaus, P.G.; Newman, D.J. Impact of natural products on developing new anti-cancer agents. Chem. Rev. 2009, 109, 3012-3043. 
4. Johnson, I.S.; Armstrong, J.G.; Gorman, M.; Burnett, J.P., Jr. The vinca alkaloids: A new class of oncolytic agents. Cancer Res. 1963, 23, 1390-1427.

5. Wani, M.; Taylor, H.; Wall, M.; Coggon, P.; McPhail, A. Plant antitumor agents. VI. The isolation and structure of taxol, a novel antileukemic and antitumor agent from Taxus brevifolia. J. Am. Chem. Soc. 1971, 93, 2325-2327.

6. Adams, D.J.; Wahl, M.L.; Flowers, J.L.; Sen, B.; Colvin, M.; Dewhirst, M.W.; Manikumar, G.; Wani, M.C. Camptothecin analogs with enhanced activity against human breast cancer cells. II. Impact of the tumor $\mathrm{pH}$ gradient. Cancer Chemother. Pharmacol. 2005, 57, 145-154.

7. Editorial Committee of the Chinese Pharmacopoeia. Pharmacopoeia of the People's Republic of China. Part 1; Chinese Medical Science and Technology Press: Beijing, China, 2010; pp. 277-278.

8. Drug Standards of the State Drug Administration of China [S]; The State Drug Administration of China: Beijing, China, 2002; Standard code: WS-10630 (ZD-0630)-2002.

9. Yuan, X.Y.; Fang, Z.Z.; Huang, X.Y. Observation on the treatment of 14 cases of advanced gastric cancer with Injection Xiao-Ai-Ping. Shanghai Med. Pharm. J. 1996, 6, 12-13.

10. Wang, W.Y.; Zhou, Y.; Zhang, X.J.; Gao, T.H.; Luo, Z.F.; Liu, M.Y. A random study of xiaoaiping injection combined with chemotherapy on the treatment of advanced non-small cell lung cancer. Chin. Clin. Oncol. 2009, 14, 936-938.

11. Han, S.Y.; Zhao, M.B.; Zhuang, G.B.; Li, P.P. Marsdenia tenacissima extract restored gefitinib sensitivity in resistant non-small cell lung cancer cells. Lung Cancer 2012, 5, 30-37.

12. Huang, T.; Gong, W.H.; Zou, C.P.; Li, X.C.; Jiang, G.J.; Li, X.H.; Qian, H. Marsdenia tenacissima extract sensitizes MG63 cells to doxorubicin-induced apoptosis. Genet. Mol. Res. 2014, 13, 354-362.

13. Xue, H.L.; Huang, X.D.; He, D.; Lin, S.J.; Wang, S.; Niu, T. Effects of Marsdenia tenacissima extract on proliferation and apoptosis of hematologic neoplasm cell line cells. Sichuan Da Xue Xue Bao Yi Xue Ban 2012, 43, 174-179.

14. Huang, Z.R.; Lin, H.; Wang, Y.; Cao, Z.; Lin, W.; Chen, Q. Studies on the anti-angiogenic effect of Marsdenia tenacissima extract in vitro and in vivo. Oncol. Lett. 2013, 5, 917-922.

15. Mao, S.L.; Lao, A.N.; Uzawa, J.; Yoshida, S.; Fujimoto, Y. Five new pregnane glycosides from the stems of Marsdenia tenacissima. J. Asian Nat. Prod. Res. 2011, 13, 477-485.

16. Luo, S.Q.; Lin, L.Z.; Geoffrey, A.; Xue, L.; Johnson, M.E. Polyoxypregnanes from Marsdenia tenacissima. Phytochemistry 1993, 34, 1615-1620.

17. Hu, Y.J.; Shen, X.L.; Lu, H.L.; Zhang, Y.H.; Huang, X.A.; Fu, L.C.; Fong, W.F. Tenacigenin B derivatives reverse P-glycoprotein-mediated multidrug resistance in HepG2/Dox cells. J. Nat. Prod. 2008, 71, 1049-1051.

18. Ye, B.; Yang, J.; Li, J.; Niu, T.; Wang, S. In vitro and in vivo antitumor activities of tenacissoside C from Marsdenia tenacissima. Planta Med. 2014, 80, 29-38.

19. Krishna, R.; Mayer, L.D. Multidrug resistance (MDR) in cancer. Mechanisms, reversal using modulators of MDR and the role of MDR modulators in influencing the pharmacokinetics of anticancer drugs. Eur. J. Pharm. Sci. 2000, 11, 265-283. 
20. Alonso-Castro, A.J.; Ortiz-Sánchez, E.; García-Regalado, A.; Ruiz, G.; Núñez-Martínez, J.M.; González-Sánchez, I.; Quintanar-Jurado, V.; Morales-Sánchez, E.; Dominguez, F.; López-Toledo, G.; et al. Kaempferitrin induces apoptosis via intrinsic pathway in HeLa cells and exerts antitumor effects. J. Ethnopharmacol. 2013, 145, 476-489.

21. Sharan, R.N.; Mehrotra, M.; Choudhury, Y.; Asotra, K. Association of betel nut with carcinogenesis: Revisit with a clinical perspective. PLoS One 2012, 7, e42759.

22. Von Euw, J.; Reichstein, T. Die Glycoside der Samen von Strophathus Nicholsonii Holm. Glycoside und Aglykone. Helv. Chim. Acta 1948, 31, 888-892.

23. Hayashi, K.; Wada, K.; Mitsuhashi, H.; Bando, H.; Takase, M.; Terada, S.; Koide, Y.; Aiba, T.; Narita, T.; Mizuno, D. Antitumor active glycosides from Condurango Cortex. Chem. Pharm. Bull. 1980, 28, 1954-1958.

24. Jiang, Y.; Ahn, E.Y.; Ryu, S.H.; Kim, D.K.; Park, J.S.; Yoon, H.J.; You, S.; Lee, B.J.; Lee, D.S.; Jung, J.H. Cytotoxicity of psammaplin A from a two-sponge association may correlate with the inhibition of DNA replication. BMC Cancer 2004, 4, 70.

25. Shen, X.L.; Chen, G.Y.; Zhu, G.Y.; Cai, J.Z.; Wang, L.; Hu, Y.J.; Fong, W.F. 3'-O,4'-O-aromatic acyl substituted 7,8-pyranocoumarins: A new class of $P$-glycoprotein modulators. J. Pharm. Pharmacol. 2012, 64, 90-100.

26. Sun, Q.; Liu, K.; Shen, X.; Jin, W.; Jiang, L.; Saeed Sheikh, M.; Hu, Y.; Huang, Y. Lappaol F, a novel anticancer agent isolated from plant arctium Lappa L. Mol. Cancer Ther. 2014, 13, 49-59.

27. Li, Q.F.; Wang, X.L.; Ding, L.S.; Zhang, C. Polyoxypregnanes from the stems of Marsdenia tenacissima. Chin. Chem. Lett. 2007, 18, 831-834.

28. Jiang, Y.; Luo, S.Q. Studies on chemical structures of three new $\mathrm{C}_{21}$-steroidal glycosides from Marsdenia tenacissima. Chin. J. Pharm. 1996, 27, 391-395.

Sample Availability: Not available.

(C) 2014 by the authors; licensee MDPI, Basel, Switzerland. This article is an open access article distributed under the terms and conditions of the Creative Commons Attribution license (http://creativecommons.org/licenses/by/3.0/). 